\title{
Independent Space Operators: Gaining a Voice in Design for Operability
}

\author{
Carey M. McCleskey ${ }^{*}$ \\ NASA, Kennedy Space Center, Florida, 32899, U.S.A. \\ William R. Claybaugh, II ${ }^{\dagger}$ \\ NASA, Headquarters, Washington, D.C., 20546, U.S.A.
}

\begin{abstract}
Affordable and sustainable space exploration remains an elusive goal. We explore the competitive advantages of evolving towards independent operators for space transportation in our economy. We consider the pros and cons of evolving business organizations that operate and maintain space transportation system assets independently from flight system manufacturers and from host spaceports. The case is made that a more competitive business climate for creating inherently operable, dependable, and supportable space transportation systems can evolve out of today's traditional vertical business model-a model within which the voice of the operator is often heard, but rarely acted upon during crucial design commitments and critical design processes. Thus new business models may be required, driven less by hardware consumption and more by space system utilization.
\end{abstract}

\section{Introduction}

$\mathrm{O}$ PERABLE, supportable, and dependable space systems have long existed on space program drawing boards, and as important objectives in industry business plans. Taking the leap from thought to reality, however, has proven very difficult. Each new attempt, whether publicly or privately funded, seemingly ends with disappointment. The system availability is far poorer than promised; spacecraft, even when successfully deployed and positioned, are often not as dependable as the business plans and program budgets had promised. Worse, the total support costs grow much higher than anticipated, with the result that the enterprises are difficult to sustain from an investment standpoint, whether private or public.

It is thus instructive to explore the operational characteristics typically designed into space systems. Just as important to address, however, are the competitive incentives and business advantages—if any — that might reward space system design trades that favor greater operability, supportability, and dependability. We will examine the nature of today's vertical space transportation industry and explore the possibilities of evolving a new competitive market segment-the independent space operator. Born out of today's operations and support experience and capabilities, this industry stakeholder (i.e., the user-operator) could exercise a strong voice during the design process and change the present outcome.

Independent operators (whether commercially or contractually independent) can have a voice in the design selection process with power over an array of competing suppliers, ultimately evolving toward real commercial purchasing power that discriminates, much as space business insurance providers are now discriminating, ${ }^{1}$ between systems with a track record of meeting expectations and those without.

\footnotetext{
* Technical Manager, Engineering Development Directorate, Systems Engineering and Integration Office, John F. Kennedy Space Center/DX-C, Senior AIAA Member.

${ }^{\dagger}$ Director, Agency Studies, Office of Program Assessment \& Evaluation, NASA Headquarters, AIAA Associate Fellow.
} 


\section{Background-the Players}

When analyzing a generic space transportation industry, general classifications of the major business players can be identified. In a later section we will examine the business incentives and design motivations of each of these in more detail. Whether the market is military, civilian, or commercial, the major players that have a direct role or a direct stake in the design process are:

1) Manufacturers/Suppliers_-focused on designing and producing the hardware product.

2) Operators - focused on making the design work, and more importantly, on developing a payload delivery service for the space transportation customer.

3) Spaceport Hosts - focused on providing the harboring facilities, systems, and equipment for one or more operators and their customers. This may be a large-scale orbital/planetary complex (e.g., Cape Canaveral or Vandenberg Air Force Base), a smaller hosts which could be an existing airports authorized for space flight operations (e.g., Mojave Airport, California)

4) Transportation Customers - requiring personnel or cargo delivery. Current examples are government agencies and commercial telecommunications providers.

\section{Is There Really a Difference Between alt.space and big.space?}

Often called into question in terms of an organization's ability to create a more effective space system is the business paradigm within which it is created. In today's space transportation market an alternative set of players, often referred to as alt.space in the political arena, ${ }^{2}$ has emerged to compete with larger, more traditional aerospace conglomerates, or big.space. Is there, however, really a difference between the two when it comes to the ability to understand the needs of the operator?

\section{A. Vertically Integrated Business Structures}

Whether large or small, space transportation providers are almost all highly vertical in corporate structure. With very few exceptions they not only design and produce the flight systems, they also operate them on the ground (or form subsidiaries to so do). The space industry does not put the flight hardware on the open market for any qualified company, such as an independent spaceline; instead, today's companies and business alliances usually design, specify and/or construct customized launch platforms, dedicated control rooms, unique assembly facilities, and dedicated propellant supply and distribution services. Still later in the development process, they design and fabricate ground support equipment. This is often accomplished with cost-plus contract commitments made with a customer well in advance of a good understanding and agreement on the quantity and complexity of flight-to-ground interfaces. Ultimately, the prime contractor (or their corporate subsidiary or affiliate) then operates and maintains their custom ground infrastructure designs on contract to the customer.

\section{B. A New Engineering and Applied Technology Paradigm Required}

The question is whether this vertical structure is truly addressing the equipment improvement needs of the useroperator segment of the industry—for both alt.space and big.space alike. The reflective case, however, also needs to be addressed, i.e., whether operations and infrastructure business managers are applying adequate engineering resources and attention to identifying and conveying needed technical improvements to the design communityboth flight and ground systems. Technology push approaches by technology managers have repeatedly been thwarted not only by a lack of analysis by the operator community (i.e., the technology pull), but also by designers not being provided adequate engineering evidence of maturity for non-traditional design options.

Engineering excellence - that questioning and probing attitude of the skilled engineer-is what will be required to influence the design characteristics of both flight and ground systems. Applied technologists are needed not only to develop the operational components and systems, but also to build the technical foundation required to thoroughly test and improve new designs and provide solid evidence that inspires engineering confidence in the innovations. In this way elegant solutions that improve all the attributes of the system throughout the life cycle become more visible and acceptable, and move from the realm of the impractical to the realm of the entirely possible.

\section{Need for Life Cycle Balance}

In other words, if the desire is to improve the attributes of the total life cycle, then we must ask whether the vertical business arrangement is the right one for today's situation? Can today's space industrial models (large or small) bring about a healthy balance between the longer-term needs of the operator during the nearer-term design process? To answer these questions, we must examine each stakeholder's overall motivations. 


\section{Business Incentives of the Major Stakeholders}

\section{A. Manufacturer's Motivations and Business Incentives}

The spacecraft or launch vehicle manufacturer's motivation is ultimately focused on production sales of flight hardware and associated software products. Sales and profits, from the manufacturer's point of view, are maximized by tying the sale of a flight directly to the sale of flight hardware-preferably expended after each flight. ${ }^{3}$ Manufacturing profits are further compounded when multiple flight elements are assembled at the launch site for each flight (such as multiple rocket engines, strap-on boosters, or multiple common elements) and thus consume even more hardware per customer order. This then creates, from a near-term perspective only, even greater hardware demand and thus more hardware sales within a given market condition.

\section{The GSE-Creep Phenomenon}

Past experience documents that ground support equipment (GSE) creep - a process where the required number of servicing and support equipment items and vendors trends upwards following the conceptual design phase, but after the sale or commitment is made. This is a subtle phenomenon with not-so-subtle--and potentially very profound--life cycle cost impacts. It can be suggested that this represents a desirable economic situation for cost-plus profit on government contracts-not only for the unplanned equipment acquisition, but also as a positive situation for the prime contractor and vendors for sustaining upkeep. It should not be inferred that this is intentional on the part of the design engineers-merely that GSE-creep, when it has surfaced in the past, has worked in the economic favor of the manufacturer/supplier.

\section{Near-Term Acquisition Issues Unnaturally Dominate Vertical Business Arrangements}

The manufacturer's, then, may prefer earning profit by holding down nearer-term manufacturing costs regardless of longer-term operations and support impacts that will likely occur well after the business commitment. This situation prevails due to the dominance of manufacturing interests in space launch business decision making.

Moreover, there is little incentive for the manufacturer to be held accountable downstream to perceived "lesser priority" operational outcomes, such as the total system responsiveness, total accumulated infrastructure and logistics support systems. While these customer demands and operator needs are held as high priorities during the conceptual design phases and design competitions, these typically become mere design goals and not design-to objectives during detailed requirements reviews and into the preliminary design phase. As long as the customer is promised a capability to deliver a payload successfully to space, and total costs are estimated to be acceptable to the customer, those characteristics that influence downstream annual operation and infrastructure costs are allowed to be treated with optimism in vertically-integrated business arrangements—-which results in critical compromises that are perceived to favor up-front acquisition issues.

\section{Dispelling a Popular Myth: What's Good for Operations is Bad for Development}

In reality, the simpler and less hazardous design characteristics that favor the operator, also tend to favor up-front development efforts because there is less design work to do: there are fewer parts; fewer subsystems and systems to analyze and specify; the tooling and fabrication work is less intense; not to mention the simpler and less hazardous testing and qualification processes. This is not news: it was observed by early rocket program managers. The German Army V-2 tactical missile development inspired one overseeing officer to write:

The whole design has apparently been done as if hundreds of people had the time to spend weeks going over the rocket on the stand, installing valves, doing assembly work, moving cables, and generally fumbling around. Cooperation between the Test Group and [the Design Department] is lacking... ${ }^{4}$

The way to lower life cycle costs across the board—from design through recurring operations—is to find means early in the design process for removing work content.

\section{B. Operator's Functions and Business Incentives}

\section{Availability and Ownership Costs}

The space transportation system operator, on the other hand, is concerned with producing profit from sales of space flights to a paying customer. This translates to a focus on ownership and operation of the space transportation system equipment and software (both flight and ground support). Repeatedly purchasing equipment, and the recurring costs to operate and support that equipment, should be minimized. The number of paid flights by a customer base is to be maximized, i.e., the system availability must reach a high enough threshold to overcome recurring support burden. Labor-intensive mission planning and flight support, as well as equipment-intensive assembly and servicing of spacecraft and launch vehicles are thus to be minimized. The labor and equipment intensity required to accomplish this falls directly out of the flight and ground system design characteristics. If, for example, the design process leaves the total number and complexity of systems and subsystems to chance, then the 
flight-to-ground interfaces are likely to accumulate quickly during preliminary design, with the end result being a disappointingly large required workforce-with a still larger workforce then required to safely sustain it all.

2. Demand for Dependability

On the other hand, operators too often appear to be too quick to accept the design status quo within today's situation, rather than pushing for improvements. A case in point is today's design approach to flight reliability. The user-operator often has a difficult time finding equipment that strikes a design balance between added layers of hardware redundancy to gain desired flight reliability on the one hand, or accepting inadequately designed critical single point failures. Added hardware (in some cases, itself hazardous) then becomes a severe but often difficult to quantify maintenance burden-ultimately adding potentially huge cumulative costs to the transportation customer. Yet operating risky space vehicles with too many single point failures is also highly undesirable.

Thus what operators should be demanding is more stringent design life requirements, improvements in overall engineering quality relative to the space environments encountered, more comprehensive and thorough testing of the designs, and programs similar in objective to the zero-defect program of Apollo. ${ }^{5}$ Today's designers and operators are beginning to feel pressure to make such changes through the space insurance industry's incipient rating of individual vehicle's based on their space mission reliability record-which is still very low from the insurance industry's point of view.

An independent operator business segment would begin culling out designs with an overabundance of troublesome hardware. They would begin building an equipment supply chain that is focused on simple system and subsystem designs with fewer parts, but with ones that have a good service record for flight and ground operations.

\section{Spaceport Host}

\section{Enabling It All To Come Together}

We need to look at another player in the space systems design process that is too often mistaken for the operator-the spaceport host. This player's function is to enable the manufacturer, the operators, and the customer to accomplish their functions safely (first and foremost) and effectively.

2. Design Roles and Responsibilities

The host's job is a difficult balance of roles and responsibilities sometimes at odds with one another during the design phase; i.e., they must balance their responsibilities for designing facilities, equipment and various support services, while at the same time recognizing that they will inherit the end result (the routine operations and infrastructure) of this work.

The industries supporting these functions are, like the flight system producer, looking to sell assets, only in this case it is new facilities, new structures, new ground equipment, and new command and control systems. Tending to be government-owned entities, the spaceport hosts' most direct industry partners during the design phase are one or more architectural and engineering firms that perform facility design and construction, ground equipment design and fabrication, and ground software development.

The design challenges here depend a great deal on the scale and complexity of the spacecraft and launch vehicles themselves. It often involves scores of separate and often exotic propellants, fluids, and gases, and literally hundreds if not thousands of flight-to-ground interfaces for a complex human-rated system. Complex, multi-element space vehicles can require a ground architecture encompassing numerous geographically-concentrated flight hardware processing stations. For the Space Shuttle the many processing stations require over 5,000 GSE items accumulated from various flight and ground element suppliers. ${ }^{6}$ It also encompasses an equal number of complex, functionallydistributed sets of systems that: control information flow; provide fire, medical, rescue, and security services during routine hazardous processing operations - if required by the vehicle design — and not just during the launch and landing events; along with many other important functions including weather services, pyrotechnic and ordnance device storage, communications and tracking, and range safety support.

\section{Summary of Stakeholder Incentives}

In short, the business motives of the space flight system manufacturers and suppliers are very different than the prime motives of system operators, which in turn are very different from the spaceport hosts—all within the same industry. How can these differences be reconciled, while increasing competitiveness and value for the transportation customer? In order to answer this question, we look at how other industries with vertical economic structures, having reached a plateau from its initial growth spurt, transformed into a different economic structure that spurred new market growth. 


\section{Historical Examples and Current Trends}

\section{A. Air Mail Act of 1934}

\section{Background}

United States commercial air transportation services in the late 1920s and early 1930s transformed from a vertically integrated structure dominated by U.S. Postal Service Air Mail to a more horizontally distributed system that legally separated the operator from the aircraft manufacturer by World II. Air transportation holding companies were formed in the late 1920s and early 1930s on a vertical business model that was shaped around U. S. Air Mail contracts passed out to industry by the U. S. Postmaster General. An example was the United Aircraft and Transport Company, a conglomerate of Boeing Air Transport and other airmail airlines, such as National Air Transport, Pratt \& Whitney, Sikorsky, among other companies. ${ }^{7}$ Another example is Eastern Airlines, owned by North American Aviation. ${ }^{8}$ The most important factor to note is that these holding companies owned the means of aircraft production, the airlines that operated its aircraft, and even (surprisingly, given local government investment in them) some private airports and airfields to

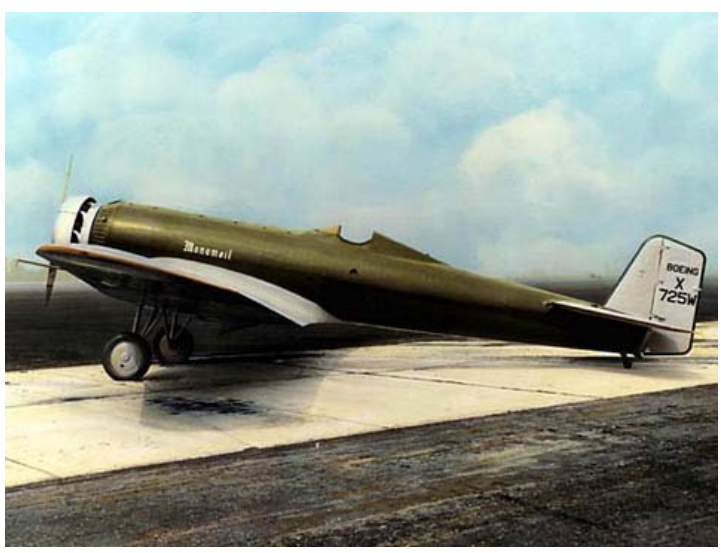

Figure 1. Boeing Monomail Model 200, 1930s

Airmail aircraft were not suited for the expanding passenger market, yet were the most lucrative for the vertical air mail market of the early 1930s complete their respective ground networks.

2. Vertical Transportation Market and "Spoils"

Contention grew when the nascent passenger air travel market was largely stifled because smaller operators could not get the manufacturers motivated to the type of aircraft they needed (particularly in terms of safety features) to convince the public that it was safe to fly. This erupted into scandal when the Postmaster General consolidated airline routes to only three selected companies at what later became known as the "Spoils Conference" in May of 1930. Their smaller competitors were forced out. This became a presidential campaign issue in the election of 1932. With a change of administrations, and in the midst of the Great Depression, a Senate investigation referred to the process of giving contracts as spoils, and further, that the contracts had been issued to the friends of the previous administration. After a short period of time the existing airmail contracts were canceled and new contracts were let forbidding simultaneous ownership of both airlines companies and aircraft manufacturing companies. After the Air Mail Act of 1934, United Airlines for example, was separated from its parent holding company. ${ }^{9}$

3. Separating the Means of Production from the Means of Operation

As a result of the Air Mail Act of 1934, the new United Airlines was free to purchase, own, and operate aircraft from whomever it wished-not just the aircraft products of a sole owner. United Airlines, and indeed by law all airlines, were now independent operators. More significantly, these independent operators were free to move into whatever markets made sense to their business model and were not confined by the needs of their aircraft manufacturer owners. These now independent companies then drove technology needs for safer aircraft designs and features, so that air transport technologists in general (and the National Advisory Council for Aeronautics, or NACA, in particular) emerged as important national economic assets in the late 1930s and beyond.

\section{B. Satellite Industry Trends}

Also of note is the telecommunications satellite operations market, where corporate and business distinctions and a separation of the means of production from the means of operations can be observed. ${ }^{10}$ Another example is the European satellite navigational information system, Galileo. There thus appears to be a emerging trend toward flight hardware procurements being intentionally separated from ground system procurements. For space transportation, this may be a trend to watch for with respect to spaceport, mission, and launch operations. 


\section{Telecommunications Development}

Additional examples outside the aerospace industry offer additional historical insight. The technology revolution in the telecommunications industry that occurred in the latter decades of the twentieth century can arguably in part be traced to the end of the vertical industry structure that existed in that industry prior to legal actions. ${ }^{11,12}$

A brief history of the Bell System and AT\&T describes the situation in moving from a vertical monopoly to a competitive

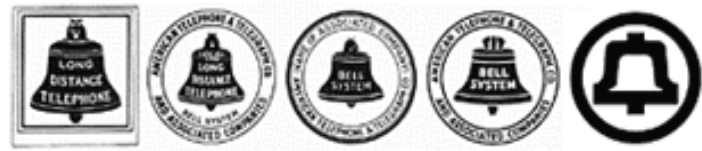

Figure 2. The Bell System Monopoly

In 1984, as a regulated monopoly, the Bell System had been largely insulated from market pressures for most of its history. market:

As a regulated monopoly, the Bell System had been largely insulated from market pressures for most of its history. Its culture venerated service, technological excellence, reliability, and innovation within a non-competitive internally-driven framework of taking however much time and money it took to get things done right. The new AT\&T had to learn how to find out and deliver what its customers wanted, when its customers wanted it, in competition with others who sought to fill the same customers' needs. ${ }^{13}$

\section{Need for Variation from Past Attempts}

The concept of independent space operators with hardware selection and/or purchasing power over manufacturers should be distinguished from past attempts to "privatize" the Space Shuttle operations. The United Space Alliance (USA) under NASA’s Space Flight Operations Contract (SFOC), and its predecessor, the Lockheed Shuttle Processing Contract (SPC), were attempts to establish separate operators. In both cases, the "operations contractor" was not involved (or even in existence) during design requirements development, nor during the design phase. The SPC contract, which came into being shortly after the Orbital Flight Test Program in the early-mid 1980s, was not in existence during the acquisition phase of Shuttle. As with today's USA contract, Lockheed/SPC had no significant independent purchasing power to search, select, or to acquire its own equipment assets.

\section{Programmatic Potential for Enabling Needed Technical/Technology Improvements}

\section{A. Overall Needs and the Independent Space Operator Strategy}

If the operator and the spaceport host are empowered during the design phase to influence the outcome relative to lower ownership costs and higher levels of dependability for their flight and ground equipment, then increased flight availability seems likely to result. Further, if the operator were provided the ability to choose the flight equipment and choose the spaceport host, then they would have the opportunity to turn the resulting increased flight availability into market growth, which in turn means real purchasing power to grow the whole industrymanufacturers, operators, and spaceports alike. This might be accomplished through a series of evolutionary steps that serve to begin separating the industry's means of production from the means of operation while still within the design process.

\section{B. Potential Acquisition Strategies (In Order of Degree of Operator Independence)}

Bringing a more influential operator's voice into the design process requires that economically viable operator's exist. Shown below are a series of cases that demonstrate an increasing degree of operator independence, equipment selection, and purchasing power:

\section{Status Quo Acquisition}

The current practice is to rely on in-house operations engineering support during requirements development for the operations functions and the facility, systems, and equipment design functions. This is followed by a period of reliance on the selected vehicle prime contractor to provide launch and recovery site operations engineering.

Simultaneous Life Cycle Acquisition

In this strategy there is continued reliance on in-house operations engineering support during requirements development for the operations functions and the facility, systems and equipment design functions. However, a separate contract for operations is let by the customer during the preliminary design phase and continues through first year or so of routine operations. That final year of the contract is the basis for performance evaluation, awards and continuation reviews and options negotiation. This independent operations contractor is provided significant selection authority, alongside the in-house operations 
engineers during design reviews, as they will have a significant stake in the design outcome they inherit. Independent Commercial Spacelines

The most aggressive approach, and the goal for the longer term, is to contract independent commercial space operators to carry out the entire process, from operations requirements development, through all phases of design, and continuing through routine operations.

\section{Specific Design Objectives}

Motivated by profit-seeking to bring about affordable and productive operations, independent space operators would tend to search for inherently operable space flight systems and technologies. For example, recent studies have begun identifying key functions and design needs associated with space transportation ground operations and infrastructure ${ }^{14}$ How independent operators might impact the major high-level functions are addressed below:

1. Unplanned Troubleshooting \& Repair Operations

Independent operators may be expected to have greater latitude to acquire dependable flight and ground hardware solutions. This in turn would initiate a transformation in how space flight systems are certified and qualified for space flight, since there would then be an emphasis on removing sources of costly unplanned hardware change-outs. Inherently reliable parts and systems, demanded by the operator, would also influence the overall operating risks and safety of the system. This should occur naturally as operators continually search for less complex systems with lower part counts and focus on demonstrated reliability rather than relying on redundant parts with lesser reliability. This contrasts with today where vehicle system and subsystem designs give rise to high part counts in opposition to the operator's needs.

Another current design problem involves inadvertently specifying that the operator should routinely replace numerous limited-life items, thus destroying the functional integrity of the system between flights, and in turn creating unplanned troubleshooting and repair, and additional system servicing.

With today's demonstrated reliability and dependability, engineering confidence in a vehicle type certification is inconceivable. Instead, each flight, due to numerous part change-outs and intrusive repair activities (many hundreds on the Shuttle Orbiter and hundreds on domestic expendables per flight), must go through a rigorous pre-flight engineering review. These flight readiness reviews (FRRs) involve nationwide engineering examinations of the entire supply chain for material and process (M\&P) variations and of assembly, servicing and checkout activities, often requiring battalions of "sustaining engineers" at the design organizations; legions of configuration managers; and regiments of safety and mission assurance experts—among others.

Independent operators would have no vested interest in hardware/part re-supply and manufacture. They would instead be motivated to invest in highly dependable parts and inherently reliable technologies. Over time, the operators would thus move the industry toward flights that involved no part removals or additions at the launch site. Once this is repeatedly demonstrated, vehicle-type certification could become a reality.

\section{Launch Vehicle Assembly and Integration Operations}

Assembly of flight elements upon arrival at the launch area is a major work contributor. This includes more than just the lift and mate operations of major flight elements, such as mating the Orbiter onto its booster/tank assembly; or the mating of a strap-on solid to a core expendable vehicle element. Flight element assembly operations have consistently required installation of ordnance devices and routing of electrical cables in systems tunnels that go across elements. Other assembly operations include application of thermal protection (spray-on, curtain installation, etc.), and installation of range safety equipment among many other time-consuming and labor-intensive activities.

Much attention has been focused on automatic mechanisms for the mating of the elements, which may well be needed for designs with many flight elements to integrate into a launch vehicle. Mating operations and functional verification of the mate should be designed to be routinely performed in a matter of minutes. Today, however, such operations (including functional verification for cryogenic propellant flow, leak-free flow of other fluids, and electrical integrity) take hours and work shifts, if not days, depending on the complexity of the vehicle design.

Thus more attention needs to be focused on designs that reduce the number of flight elements per launch. This will tend to be desired by independent operators in order to reduce costs, in turn bringing about a "no assembly required" policy at the spaceport. Operators also need designs for reliable, dependable separation systems that eliminate the use of ordnance devices. Again, this would aid the independent operator by eliminating the need for time-consuming, profit reducing, and hazardous facility and area clears involved with the installation and checks of such hazardous designs.

There likewise is a need for additional emphasis in researching alternative means of thermal protection, as compared to the complex, process-variant and time-consuming spray-on foam application techniques, as is practiced today. 


\section{Servicing Operations}

One of the great needs of an independent operator (as opposed to a government or dependent operator) is the reduction in ground servicing operations. These include simplified propellant loading operations with far fewer, less labor-intensive thermal conditioning tasks; far fewer dedicated power management fluid energy loading tasks, such as filling, draining, system pressurizations and purges. The Space Shuttle Orbiter, for example, has 402 interfaces with the Orbiter Processing Facility (OPF), most of which relate to fluid and gas system servicing. While contemporary expendable vehicles are generally less interface-intensive than the decades-old Orbiter, the number of hoses, ducts, and service arms for expendables, still allow considerable room for improvement. Independent operators--given the opportunity--would tend to seek elimination of the overabundance of interfaces, dedicated umbilicals, and swing arms.

Significant reductions in servicing operations costs require wholesale elimination of dedicated subsystems, with consolidation of functions. The objective is to eliminate dedicated working fluids and systems of parts when a more robust and flexible set of parts in a similar system could perform the same function. Some of the solutions may be the result of simpler, smarter design practices, while others may prove to be technologically challenging. For example, the general layout of a vertically-launched propulsive vehicle often elevates the liquid oxygen tank. When this is done, dedicated anti-geyser flight and ground hardware, with resulting added operations, inhibit the operator's ability to conduct simple propellant loading and conditioning operations. Careful, up-front conceptual design might eliminate entire subsystems on the vehicle, and on the ground, if operability were the highest priority.

Other potential solutions require more technology development and demonstration. For example, the elimination of hydraulic and pneumatic equipment in favor of more-electric solutions offers tremendous potential to simplify the overall power management architecture of space transportation systems (Figure 4).

\section{Functional Verification Operations}

Checkout and inspection operations, two of the more highly visible functions of the ground crew, are directly dependent not only on the flight criticality of a system or function, but also on the engineering confidence of the overall design.

If the degree of unplanned repair work is high enough (and it only takes a total of one or two items routinely per flight to qualify), then the overall system cannot be depended upon to function without conducting detailed system checks.

With today's high level of parts replacement, engineering practice over the years has instilled a significant amount of confidence-building test, checkout, and inspection operations as the vehicle is built-up and serviced for flight. If a system typically leaks, then routine, time-consuming, and labor-intensive leak checks are required. If high-traffic internal compartment servicing is designed into the vehicle, and nicked wires, dented ducts and other collateral damage typically results, then pre-closeout "confidence runs" that power up the systems are often used as good practice to prevent major interruptions during the launch countdown.

The overall strategy of a profit seeking independent operator is potentially different: 1) demonstrate vehicle processing without destroying the integrity of the flight vehicle and its systems, and, 2) embed component health monitoring with system-level health management technologies for both the flight and ground elements of the architecture.

The focus of an independent operator is likely to be on validation of health management systems that provide confidence that the system has maintained functional integrity, thus avoiding having to destroy the structural or functional configuration of the vehicle to verify proper operation. On the other hand, premature deployment of novel technical solutions can put the operator in a worse position by forcing continued troubleshooting of immature instrumentation (i.e., the "red light" comes on often enough to lose confidence in the total system design and technology).

\section{Setting up an Applied Technology Pipeline}

The technology focus for the operationally effective systems likely to be required by independent operators is going to be most challenging at the mid- to high-levels of technology readiness. While the industry has a wealth of capability in deriving new technology components and materials, the technology integration infrastructure has deteriorated severely over recent decades. This offline infrastructure is needed to reduce engineering risks through a disciplined technology integration process that includes test and evaluation of interactions among components, software algorithms and natural environment effects. With that in mind, independent operators might proceed under one of the two following assumptions:

1) Manufacturers have today all the technology on the shelf they need to succeed, and therefore, independent operators are free to immediately purchase highly operable, dependable, and supportable vehicles and ground equipment. 
2) The technology integration and application gap is somehow closed for major subsystem and system design disciplines, such as structures and mechanisms, propulsion, power management, thermal management, communications, safety management and control systems, and so forth. (Likely only with the proper forcing function - such as the emergence of independent operators).

The first state would be appropriate for commercial independent space operators, while the latter state would more appropriately correlate with public-private endeavors.

\section{Conclusions}

The achievement of low cost, operationally responsive space launch systems appears to be a natural consequence of the presence of commercial independent space launch operators. While this is not a necessary condition, we argue that it is sufficient because the profit seeking motive of such operators will drive them toward investments that lower operational costs.

This in turn suggests that while highly operable space launch systems may be developed within the existing vertically integrated manufacturing and launch organizations, it is less likely because profit seeking drives such organizations toward maximizing both the number and the value of expended hardware items. Thus complexity in design is at least implicitly—and possibly explicitly—favored over simplicity.

Finally, we observe that in the absence of a secular change in the regulatory environment the development of independent operators appears to be stifled. A vision for organizing the industry to naturally encourage business case closure for all segments of the space launch industry, and the consequent emergence of architectures that lend themselves to the needs of the operator offers the promise of overall system affordability and sustainability. 


\section{References}

${ }^{1}$ De Selding, P. B., “Inmarsat Insurer Gambles on New Assessment Tool,” Space News, Vol. 17, No. 11, 20 Mar. 2006 , p. 6.

2 The Economist (U.K.), “Who's Who in the 'alt.space' Movement,” June 16, 2004.

${ }^{3}$ EADS Space Transportation Press Release, "EADS to Win 3.0-billion-euro Contract for 30 Ariane-5 Rockets, Paris, France; May 10, 2004

${ }^{4}$ Nuefeld, M. J., The Rocket and the Reich, Peenemunde and the Coming of the Ballistic Missile Era, Harvard University Press Cambridge, MA, 1996, p. 158-9.

${ }^{5}$ PBS Online, "American Experience, Race to the Moon," URL: http://www.pbs.org/wgbh/amex/moon/peopleevents/e_houston.html [cited 22 September 2005].

${ }^{6}$ Standard Task File, Space Shuttle Ground Support Equipment, Preventive Maintenance Schedule, STF S6013, NASA Kennedy Space Center, 2003.

${ }^{7}$ Rumerman, J., U.S. Centennial of Flight Website, essay, “Boeing Military Aircraft in the 1930s and 1940s,” U.S. Centennial of Flight Commission, URL: http://www.centennialofflight.gov/essay/Aerospace/boeing-1930s_1940s/Aero19.htm , [cited 8 Apr 2006].

${ }^{8}$ AT\&T History website article, “AT\&T A Brief History: Positive Divestiture,” URL: http://www.att.com/history/history4.html, AT\&T Knowledge Ventures, [cited 8 Apr 2006].

${ }^{9}$ Anonymous, "Profile of Some of the Major Airlines in the United States, Both Past and Present: Eastern Airlines," AvStop Magazine Online, URL: http://avstop.com/History/HistoryOfAirlines/Eastern.htm , [cited 2001].

${ }^{10}$ Bates, J., "Separate Procurements Fueling Ground Systems Competition,” Space News, Vol. 15, No. 17, 26 April 2004, URL: http://www.space.com/spacenews/archive04/competitionarch_051004.html.

${ }^{11}$ Bingaman, A. K, “Competition and the Telecommunications Revolution," address by Assistant Attorney General, Antitrust Division, U.S. Department of Justice, before the Networked Economy Conference, Washington, DC, URL: http://www.usdoj.gov/atr/public/speeches/0113.htm , 26 Sep 1994.

12 Thierer, A. D., "Unnatural Monopoly: Critical Moments in the Development of the Bell System Monopoly," The CATO Journal, Vol. 14, No. 2, URL: http://www.cato.org/pubs/journal/cjv14n2-6.html, Fall 1994.

13 AT\&T History website article, “A Brief History: Positive Divestiture,” URL: http://www.att.com/history/history4.html, AT\&T Knowledge Ventures, 2006.

${ }^{14}$ McCleskey, C. M., “Space Shuttle Operations and Infrastructure: A Systems Analysis of Design Root Causes and Effects,” NASA TM-2005-211519, April 2005. 